\title{
THE NATURE OF RESIDENTIAL TIKAL: A SPATIAL ANALYSIS
}

\author{
J. JEFFERSON MACKinNon \\ University of Wisconsin
}

This study reports the results of the application of some methods of spatial analysis to the map of Tikal produced by the Tikal Project and published in 1961 (Carr and Hazard, 1961), in an attempt to gain a better understanding of the nature of residential Tikal in Classic times.

As in Puleston (1973: 22-24), the following terms will be used in this paper. Epicentral Tikal will refer to the ceremonial core of the site and its assumed elite residences. North-south and east-west axes were drawn from the center of the Great Plaza; the limits of epicentral Tikal would extend $0.40 \mathrm{~km}$ on the south axis, $0.75 \mathrm{~km}$ on the west axis, $0.50 \mathrm{~km}$ on the east axis, and $1 \mathrm{~km}$ on the north axis. The axes correspond to the survey strips which Puleston mapped and studied. Residential Tikal extends from epicentral Tikal to the site boundaries, defined by Puleston as the line outside of which there are more than 2 has. of cultivated land per residential structure coupled with the line of the defensive earthworks to the north and south of the center of Tikal (Puleston, 1973: 19; Puleston and Callender, 1967). The unmodified name Tikal will refer to a combination of residential and epicentral Tikal. Intersite areas are areas not continuously covered by remains of structures as between the boundaries of residential Tikal and Uaxactun, regardless of whether it may be demonstrated that these areas fall within the political jurisdiction of a particular site.

\section{The Reliability of the Map}

The first step in this study was to assess the reliability of the map, as suggested by Hodder and Orton (1976: 17). Two seasons of slow 
and methodical effort with plane table, alidade, and transit were dedicated to producing as accurate a map as possible in an area so densely overgrown that every sight line had to be out with machetes. The mapping procedures for the inner $18 \mathrm{~km} .{ }^{2}$ of the site are described in detail in Tikal Report No. 11 (Carr and Hazard, 1961: 1.6). Excavations by Haviland (Haviland, 1965) in parts of the mapped area found that out of a sample of 117 mapped structures, four turned out to be natural features ( $3 \%$ error), and 10 more structures were found (9\% error) that did not appear on the map. Of the 26 unmapped structures known at the time Puleston wrote (1973: 165), all were abandoned by A. D. 770 (Haviland, 1970: 192), roughly the time, as will be seen below, when all the mapped structures were in use. Puleston felt that unmapped structures only slightly influence the view of the settlement pattern presented by the Tikal map. He pointed out that the unmapped structures usually occur in open spaces where one would expect them to, "given the average spacing of plaza groups" (Puleston, 1973: 166).

Unmapped structures occuring as part of a group of mounds built around a plaza would not affect the validity of this study since areas of entire housemound groupings were measured. A missing mound or one side of a grouping would not greatly affect measurements of a group's area since the existence of a plaza in all but single mound groups was assumed. Likewise, a missing mound in a group would not affect the measurement of distances from one mound group to another which were used in the nearest neighbor analysis Thus, it was felt that the map was sufficiently reliable for the purposes of this study, if the outer $32 \mathrm{~km}^{2}$ of the $1 / 6250$ map of Tikal which was mapped by reconaissance methods rather than by plane table and alidade was deleted. Here it was likely that a greater number of structures were overlooked.

It was next considered whether all the mapped structures were inhabited contemporaneously. Haviland, who did the major excavation of residential structures, argued that $93 \%$ of the mapped structures were inhabited at the same time (Haviland, 1963: 502; 1969: $424 ; 1970: 191)$. For a discussion of this question, see Haviland (1963: 366-369, 500; 1969: 429; 1970: 191; 1972: 262), Puleston (1974: 152.60), and Turner (1976); the archaeological, ethnohistoric and ethnographic evidence presented in these works strongly suggests that from $93-98 \%$ of the mapped structures were in use in Classic times. 


\section{An Attempt to Produce a Typology of Mound Groupings by Area}

Areas of all mound grupings in each of the nine quadrangles of the $1 / 2000$ maps were measured in hopes of establishing a typology based on area. The results followed almost perfectly a Poisson Distribution. There were no significant break points and area types had to be chosen arbitrarily. In some areas of the map, very large housemound groups appear to be surrounded by smaller groups. Just as frequently, however, large housemound groups are located quite close to each other. One cannot visually divide the groupings into clusters which are arranged hierarchially.

The variation in size and structures of the housemound groupings have been taken to indicate distinctions in the prestige of the householders (Haviland, 1970; Sanders, 1976: 344). Haviland points out that some of the larger groupings even have smaller mounds with pole-and-thatch dwellings that look like attached servants' or clients' quarters associated with them. While stratification may have existed at Tikal, general conclusions could not be derived from area or location of groupings which clarifies the hierarchial structure of residential Tikal.

The size of the housemound groupings and the materials used in their construction are not very reliable indicators of status. Except for the very large groupings (over $1000 \mathrm{sq} . \mathrm{m}$. in area), the size and number of structures in a group are probably much more a function of the size and growth of the family, availability of materials (see section on quarry sites, below), and the amount of energy the family was willing to expend. Status may have had little to do with the procurement of building materials since they were readily at hand, unless one of the adjuncts of higher status was the ability to command more labor. Household and burial artifacts would be better indicators of status in the residential area of Tikal.

Millon's (1976) work at Teotihuacan is of theoretical and methodological interest on this point. Here he has tentatively identified peripheral apartment compounds of lower status individuals in comparison to apartment compounds nearer the heart of the city. He concludes, however, that the status structure of the settlement pattern at Teotihuacan had more of a mosaic quality than a gradation in status from center to periphery (Millon, 1976: 220). If size and elaboration of plaza grouping correlates with status at Tikal, then the same mosaic quality is present here. Because of the unique settlement plan of Teotihuacan, a point which Millon stresses, it should not be expected that 
work at Teotihuacan will generate direct parallels to the settlement pattern of Tikal.

For calculation purposes, housemound groupings were divided by area into the following categories:

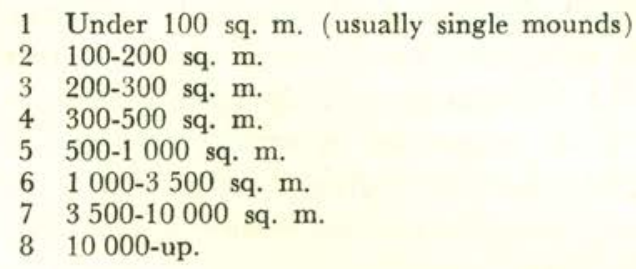

In most of my calculations, however, the exact area for each group. ing was used rather than this typology.

\section{Nearest Neighbor Analysis}

A nearest neighbor analysis was performed for 146 structure groupings in the Temple of the Inscriptions and Camp quadrangles. These quadrangles were chosen because inspection indicated that results would be least distorted by boundary effect (Hodder and Orton, 1976: 41-42), and for the following reasons:

1. There were few, and in some squares, no structures to the east due to the presence of bajos.

2. The Temple of the Inscriptions was the only large ceremonial structure in the area chosen.

3. Possible groupings of smaller structures around larger ones were noted.

4. Only 13 groupings were closer to the boundary than to their nearest neighbor.

5. The terrain is gently sloping and topography should not have been a factor influencing placements of groupings.

6. Haviland's excavation of housemounds occurred in the Camp quadrangle; thus archaeological data is available.

7. The area contained the full range of mapped features-causeways, pyramids, chultunes, reservoirs, bajos, vaulted and nonvaulted house structures, grouped and single mounds, etc.

In measuring the area of these quadrangles for the nearest neighbor analysis, the area occupied by the Inscriptions and Tikal Reservoirs, 
the Mendez Causeway, the plaza of the Temple of the Inscriptions, and the areas of the bajos were measured with the planimeter and subtracted from the total area. This was done because it was feared that clustering would be shown because housemounds were obviously not built in these areas.

The spacing of the housemound groupings was delineated by use of the Nearest Neighbor Index $\underline{R}$ following Price (1978: 3) and Whallon (1974: 18-19). Distances from each of the 146 groupings to its nearest neighboring grouping were measured. $\underline{R}$ equals the actual average distance between nearest neighbors divided by the expected average random distance:

$$
R=\frac{\bar{r}_{0}}{\bar{r}_{e}}
$$

where $\bar{r}_{0}$ is the average distance between all housemound groups measured and their nearest neighboring housemound groups. The value for $\bar{r}_{\mathrm{e}}$ was found by the formula:

$$
\overline{\mathrm{r}}_{\mathrm{e}}=\frac{1}{2 \sqrt{\mathrm{N} / \mathrm{S}}}
$$

where $\mathrm{N}$ is the number of housemound groupings and $\mathrm{S}$ is the area of the two quadrangles tested.

The values of $\underline{R}$ range as follows:

$$
\begin{aligned}
& 0.0 \text { - completely clustered distribution } \\
& 1.0 \text { - completely random distribution } \\
& 2.15 \text { - completely uniform distribution }
\end{aligned}
$$

The value found for the 146 groupings of the Temple of the Inscriptions and Camp quadrangles was $\mathrm{R}=1.4144$. The statistical level of significance of this degree of non-random spacing was tested as suggested by Whallon (1974: 19) using the formula:

$$
\mathrm{C}=\frac{\overline{\mathrm{r}}_{\mathrm{o}}-\overline{\mathrm{r}}_{\mathrm{e}}}{\delta \overline{\mathrm{r}}_{\mathrm{e}}}
$$

where $\delta \vec{r}_{0}$ is the standard error of the mean for the distances to nearest neighbors in a population of the same density as the observed population having randomly distributed items. This value is found by the formula: 


$$
\text { o } \overrightarrow{\mathrm{r}}_{\mathrm{e}}=\frac{0.26136}{\sqrt{\mathrm{Nd}}}
$$

$\left(\mathrm{N}=\right.$ number of items in population, $\mathrm{d}=\frac{\mathrm{N}}{\mathrm{A}}, \mathrm{A}=$ area $)$.

The result for $\underline{\mathrm{C}}$ was 9.5655. Reference to a table of Areas and Ordinates of Standard Normal Curve under column z shows that the result 9.5565 is significant at greater than 0.01 . Nearest neighbor analysis therefore suggests that the housemound groupings in the Temple of the Inscriptions and Camp quadrangles are regularly (uniformly) spaced over the landscape, excluding bajos and other areas where housemounds could not be constructed.

\section{Nearest Neighbor Analysis and the Boundary Effect}

Hodder and Orton (1976: 41.43) and Diggie (Hodder and Orton, 1976: 246-247) discuss the effect of imposing a boundary on the study area of a nearest neighbor analysis. The nearest neighbor analysis was run twice, once using all the sites within the chosen area and once without those closer to the boundary than to their nearest neigh. bors. The result with all 146 groupings included was (1) $R=1.4144$. Removing 13 groups that were closer to the boundary gave (2) $\underline{\mathrm{R}}=1.3343$. Result (1) produced a significance level of 9.5655 and result (2) produced a level of 7.3663. Both show significantly nonrandom spacing. The number of groups affected was only 13 out of 146 .

An important evaluation of the use of the nearest neighbor statistic in archaeology appeared following the completion of my study (Pinder et. al., 1979). The methodology and assumptions of my study compared favorably with their suggestions. Those interested in further discussion of the boundary effect should consult Pinder et. al. (1979) who report that boundary effect builds in a significant amount of underestimation, particularly when point populations are small. In the present study, a relatively large point population was the case except in the nearest neighbor analysis of the reservoirs and aguadas where $\mathrm{N}=14$ and two reservoirs were nearer to the border of the map than they were to their nearest neighbors.

The problem noted by Pinder et. al. (1979: 435) of incorporating a false element of clustering in the calculation of $R_{e}$ was avoided be- 
cause the area studied lies well within the area covered by the total population. The problem of injudicious inclusion of zones that cannot contain points was resolved by removing the areas of the bajos from my calculations. The magnitude of the deviation between $R_{0}$ and $R_{e}$ at the $95 \%$ condifence level was tested as well as they suggested.

Following the completion of this analysis, it was learned from Wendy Ashmore (personal communication) that three students of Dennis Puleston's at Minnesota had initiated in 1976 a computer study of Puleston's survey strips using similar methods of nearest neighbor analysis (Stein, Moody, and Walsh; MS. a, MS. b). The study was unfortunately not completed due to Puleston's death and therefore did not reach firm conclusions, but their preliminary results did not contradict the findings of this study.

\section{Implications of Regular Spacing of Housemounds in Residential Tikal}

Stierlin (1964: 179) coined the term "garden city" to describe the settlement pattern of Tikal. He sees the pattern to have been freely and naturally related to the environment, calling it "humane" and answering to the best ideas of modern town planning:

The layout is none other than that of the pedestrian precinct with its landscaping and free design, its alternation of esplanade and hills, cultivated ground and trees, and at Tikal, the Maya even included reservoirs in a plan of remarkable diversity... Cleanliness, coolness, and a feeling of space foreshadow the best developed rules of modern town-planning (Stierlin, 1964: 180).

The results of this nearest neighbor analysis, which indicated regular spacing for the housemound groups of Tikal, strongly supports Stierlin's concept of Tikal as a "garden city", an opinion that many archaeologists are coming to hold as well. In the light of present evidence, the subsistence mode termed "infield gardening" (Bronson, 1978: 290) or "kitchen gardening" (Puleston, 1973) best explains why the housemound groupings are spaced in a regular manner. Re. cent studies have largely demolished the old view that the Maya of Tikal were solely slash-and-burn agriculturalists (Hammond, 1978; Turner, 1978). Certainly the mapped area of Tikal is too densely set. tled for this type of agriculture (Turner, 1978: 17).

The old view was that tropical forests were poor environments for cultivation and capable of supporting only a small population. There- 
fore it was asserted that civilizations have rarely emerged in tropical areas, and when they have, they could only exist for a short period of time before collapsing. A consensus is now developing which rejects the application of the above view of the Maya and maintains that the tropical environment offered a wide range of resources and that a number of techniques could have been developed to exploit it, some of which were highly efficient usages of land and labor.

\section{Available Land per Person at Tikal}

Based on Puleston's figures (1973: 196-219), we have a settlement density of 170.5 structures $/ \mathrm{km}^{2}$ for the welldrained uplands of residential Tikal. Adding escobal bajo, an intermediate form of bajo between upland forested areas and the lowest and wettest tintal bajo, the density drops to 121.7 structures $/ \mathrm{km}^{2}$, assuming $99 \%$ occupation of structures at one time. Removing areas covered by structures but not taking into account space which might have been occupied by quarries and trails, the amount of upland and escobal bajo available per structure is 0.82 ha. ( 2.03 acres). If escobal bajo, which Puleston (1973: 198) feels was marginal for agriculture and may have been used for high-risk cultivation, is removed, only 0.59 ha. (1.45 acres) remain per structure.

The results of my nearest neighbor analysis, indicating uniform spacing, supports the validity of making estimates of available land per residential structure as Puleston has done. Calculations of available land per structure for the quadrangles studied were: 0.41 ha. structure Temple of the Inscriptions, 0.31 ha./structure Corriental, 0.65 ha./structure Camp, and 0.63 ha./structure Perdido. These figures are well within the range of 0.13 ha.-15.32 ha./structure which were computed from Puleston's survey strip figures for the average amount of cultivatable upland per structure in his north and south survey strips in Late Classic times. These calculations assumed $99 \%$ habitation (as did Puleston, 1973: 440) and that 16\% of all mounds were not residences (Rice, 1978: 42; Haviland, 1970: 193). This would give figures of cultivatable land per person, based on 5.4 people per residential structure of : 


\begin{tabular}{lcc} 
Quadrangle & $\begin{array}{c}\text { Cultivable } \\
\text { land/person }\end{array}$ & $\begin{array}{r}\text { People } \\
\text { per ha. }\end{array}$ \\
\hline Temple of the Inscriptions & 0.08 ha. & 13 \\
Perdido & 0.12 ha. & 8 \\
Camp & 0.12 ha. & 8 \\
Corriental & 0.06 ha. & 17 \\
\hline
\end{tabular}

Puleston's measurements of the annual yield of ramón trees showed that they could produce far more than necessary to meet the nutrition requirements for these numbers of occupants per housemound group given these figures of available land. Experimental work with chultunes showed that they were effective storage places for ramón seeds and that there was a correlation between them and existing ramón trees (Puleston, 1965, 1971, 1973). Puleston's ramón argument is strong, but ethnohistorical evidence indicates that ramón was considered an emergency or famine food and was not a major food source in times we have records for. Given Puleston's figures, it seems unlikely that the association of ramón trees with abandoned Maya settlements is simply due to the tree's possible affinity for disturbed soil, an assertion which has not been proven. Certainly dietary preferences could have changed since late Classic times, but it is far more likely that the spaces between structures in residential Tikal were given over to intercropping of a number of useful plants and trees, including (but not exclusively) ramón. Puleston's figures for ramón production do show that the spaces between the housemounds could produce enough food to feed the population and leave a surplus besides. Intercropping could raise the figures even higher.

The surface layers of undisturbed soils in the Tikal area contain as much as $30 \%$ organic material and are therefore highly fertile. Comparison with modern milpas under cultivation at Tikal showed a dramatic decline in nutrients when the tropical forest was cleared, burned, and cultivated. Soil color became much lighter and surface temperature increased as well. This increase would increase the oxidation and volitization of nutrients and cause transpiration ratios to increase as well. Better management of these soils would be to maintain the tree cover through the use of tree-crops and multi-story utilization (for data, see Puleston, 1973: 225, Table VII).

Disturbed soils in the Tikal area have not recovered their original fertility in over a thousand years. Some of the mound groups, plazas, causeways, etc., show a lighter colored surface horizon than adjacent areas which were undisturbed by the Maya. It is possible that the 
darker horizon was stripped from areas where construction was to take place and utilized elsewhere. This seems generally suggested by the archaeological evidence (Puleston, 1973: 262).

The upland soils which the Maya favored for habitation are of silt loam and range from about 0.28 to $0.5 \mathrm{~m}$. in depth to bedrock. Puleston's study of the distribution of settlement and ramón trees in relation to soil type and soil constitutents produced no significant results or correlations. Phosporus content of the soil was not higher in habitation areas (Puleston, 1973: 263). Redistribution of nutrient elements in the soil over the past 1000 years due to the heavy rainfall probably accounts for this. Thus modern fertility studies are unlikely to correlate with structures. Puleston (1973: 268) suggests that if kitchen gardening was practiced in residential Tikal there may have been no phosporus build up because when kitchen scrapings and human excrement were recycled in the garden the expected phosporus build up never occurred.

Using Olson's (1969) soil maps and data, the relationship between the location of structures and soil and slope characteristics were studied as follows:

\begin{tabular}{lccc}
\hline & $\begin{array}{c}\text { \% of Land } \\
\text { in Cent. } \\
9 \mathrm{~km}^{2} \text { with } \\
\text { this slope }\end{array}$ & $\begin{array}{c}\text { \# of strs. TI, } \\
\text { Camp } \\
\text { Perdido quads } \\
\text { on this slope }\end{array}$ & $\begin{array}{c}\text { \% of strs. TI, } \\
\text { Camp Perdido } \\
\text { quads this slope }\end{array}$ \\
\hline A $0.3 \%$ & 33 & 116 & 28 \\
B $3-8 \%$ & 33 & 189 & 48 \\
C $8-15 \%$ & 25 & 104 & 25 \\
D $15-25 \%$ & 8 & 5 & 1 \\
Reservoirs, Aguadas & 2 & 0 & 0 \\
\hline
\end{tabular}

The Tikal Maya apparently avoided slopes greater than 15\% whenever possible. Otherwise, they seem to have placed their structures uniformly over the landscape, unconcerned with slopes of less than $15 \%$. Practically any form of substance should be feasible on these gentle slopes. Well-drained soil seems to have been favored as building sites and by implication, for associated kitchen gardens.

The following Table presents the relationship between soil type and structures: 
TEMPLE OF THE INSCRIPTIONS QUADRANGLE

\begin{tabular}{cccc}
\hline Olson soil type & $\begin{array}{c}\text { \% of land of } \\
\text { type in quad }\end{array}$ & $\begin{array}{c}\text { \# of } \\
\text { structures }\end{array}$ & $\begin{array}{c}\text { \% of } \\
\text { structures }\end{array}$ \\
\hline 1 & 5 & 9 & 3 \\
4 & 37 & 198 & 56 \\
5 & 20.5 & 16 & 6 \\
8 & 6 & 11 & 4 \\
10 & 7 & 0 & 0 \\
18 & 10 & 24 & 12 \\
19 & 15 & 51 & 19
\end{tabular}

CAMP QUADRANGLE

$\begin{array}{rcrr}1 & 9.5 & 8 & 5 \\ 4 & 14 & 57 & 38 \\ 5 & 18.5 & 8 & 5 \\ 18 & 1 & 17 & 12 \\ 19 & 13 & 61 & 40\end{array}$

PERDIDO QUADRANGLE

$\begin{array}{rrrr}1 & 8 & 10 & 6 \\ 2 & 1 & 0 & 0 \\ 4 & 27 & 39 & 22 \\ 5 & 20 & 33 & 19 \\ 6 & 4 & 4 & 2 \\ 8 & 0.5 & 0 & 0 \\ 10 & 16.5 & 0 & 0 \\ 11 & 0.5 & 11 & 6 \\ 18 & 5 & 36 & 22 \\ 19 & 17.5 & 40 & 23\end{array}$

SOIL TYPES AT TIKAL (Olson, 1969)

1. Well drained clay loam upland soil 18 in. to soft limestone.

2. Well drained silt loam disturbed alluvial soil 51 in. to soft limestone.

4. Well drained silt loam upland soil 11 in. to hard limestone.

5. Somewhat poorly drained clay swamp soil 19 in. to soft limestone.

6. Well drained silt loam disturbed upland soil $57 \mathrm{in}$. to soft limestone.

7. Moderately well drained clay upland soil deeper than 60 in. to soft limestone.

8. Well drained silty clay loam upland soil 16 in. to soft limestone.

10. Poorly drained clay swamp deep to soft limestone.

11. Very poorly drained clay swamp (water hole) soil deep to soft limestone.

18. Well drained silt loam disturbed upland soil formed in soft silt loam limestone material.

19. Well drained silt loam upland soil 26 in. to moderately hard limestone. 
Land types which seem favored are types 18, 19, and 4, the welldrained silt lean upland soils. Thicker soils (more depth to bedrock) seem to have been favored as well. Of the upland soils, none were identified that were unsuitable for agriculture, but the results of the soil survey and the fertility data presented by Olson (1969) are not suitable for detailed study. It simply appears that all of the upland soils were suitable for agriculture as far as factors of slope and soil constituents are concerned. Structures seem generally uniformly dis. tributed over the available soils, percentage of structures not departing greatly from percentage of soil type on which they were built, except that areas with deeper soil and well-drained silt loam were somewhat favored.

\section{Further Implications of the Tikal Settlement Pattern}

Sanders (1973: 329) argues that the most convincing evidence of contemporaneity in an archaeological site is the integration of housing units in the overall planning. While there does not appear to be a plan to residential Tikal in the formal sense, one could argue that the results of the nearest neighbor analysis, which indicates regular spacing, would support the contemporaneity of the housemound groupings.

To return to Steirlin's garden city analogy, we could say that the Maya were not an urban people at heart. There were advantages, possibly even compelling reasons, for living close to the heart of a large ceremonial center like Tikal, but they had no desire to live closely packed together. Vogt, in his study of Zinacantan settlement patterns (Vogt, 1968) makes much of the fact that he sees the Mayans as small hamlet dwellers, retaining behavior based on this trait even in environments where it was not appropriate. He projects this into the past. The distribution of housemound groupings around central Tikal does not imply an authoritarian regime closely controlling its subjects. The settlement pattern seems freely and naturally related to the environment in keeping with the subsistence system suggested above.

Hamblin and Pitcher (1980) argue that class conflict was the probable cause of the Classic Maya collapse. Paying little attention to the time span involved in the Classic period at Tikal, they postulate that a population explosion caused a land squeeze that led to peasant revolt. They suggest that the economic system became based on long distance trade and a shift from milpas to intensive agriculture managec by the elite. This resulted in displacement of peasants from their land. 
and their increasing exploitation as an agricultural proletariat, placing them in a socially disorganized position.

One must ask if the above picture is consistent with the uniformlyspaced settlement pattern of residential Tikal which this study has revealed. The grouping of housemounds around paved plazas containing small ceremonial structures does not suggest social disorganization. Where is the evidence of land squeeze? Where are the closely-packed hovels of peasants displaced from their land and dependant upon an elite they are becoming increasingly resentful of? The areas of intensive agriculture which the agricultural proletariat worked for its masters have yet to be positively identified. There appears to have been enough space between the housemound groupings for the inhabitants to grow their own food, using some form of intensive agriculture not requiring great social organization, such as kitchen gardening and arboriculture, preserving a varied plant cover similar to the original forest. This would protect the soil and take maximum advantage of varying sunlight, nutrient, and moisture requirements of a mixture of plant types. If this type of subsistence was practiced between the houses of Tikal, it implies that all the Maya of Tikal, except the inhabitants of the palaces, were to a large extent capable of meeting their food requirements regardless of the economic or political system unless taxation in the form of food was heavy. To term people with this capability an "agricultural proletariat" may not be accurate. It is not the purpose of this paper to discuss the Classic Maya collapse, but it should be pointed out that theories based on population pressure and exploitation of the masses must explain how these factors are consistent with the nature of the residential and intersite areas of a major center like Tikal.

\section{Distances between Groupings of Varying Size}

The average distance between Bullard's "ordinary house ruins" and his "large house ruins prominent in cluster-type groupings" (or between my types 1.5 and type 6 ) for the 146 groups in the Temple of the Inscriptions and Camp quadrangles was measured and found to be $207 \mathrm{~m}$. Types 1,2 , and 5 were measured separately for distance to type 6 groups to see if size of housemound group was related to distance from large house ruins. As the table below reveals, there were no significant differences, further supporting a regular distribution.

T-tests were employed to compare the differences in means. The mean of the 135 type 1.5 groupings was compared to the mean of 
the type 6 groupings: $t=0.3337$, the required value for 134 degrees of freedom $=1.960$, therefore the null hypothesis that the means were equal could not be rejected. The means of type 1 and type 6 groupings were compared: $\mathrm{t}=0.4884$, required value with 26 degrees of freedom $=2.056$, therefore the null hypothesis that the means were equal could not be rejected. For type $1 \mathrm{vs}$. type 2 means, $\mathrm{t}=0.0999$ and for type $1 \mathrm{vs}$. type $5, \mathrm{t}=0.4056$. The required value at the 0.05 confidence level in all three type 1 tests was, as stated above, 2.056.

\section{AVERAGE DISTANCE FROM LARGE (Type 6) HOUSEMOUND GROUPS}

Type $1 \quad$ (single mounds)
Type $2 \quad\left(100-200 \mathrm{~m}^{2}\right)$
Type $5 \quad\left(500-1000 \mathrm{~m}^{2}\right)$
Types $1-5$
Type $6 \quad\left(1000-3500 \mathrm{~m}^{2}\right)$

$186.74 \mathrm{~m}$. $197.26 \mathrm{~m}$ $229.42 \mathrm{~m}$. $202.24 \mathrm{~m}$. $238.13 \mathrm{~m}$.

Size of grouping does not appear to affect distance of ordinary housemound groupings from prominent large housemound groupings. Larger housemound groupings tend to be slightly farther away from each other, which may simply be a function of frequency of occurrence.

\section{Area of Groupings in Relation to Elevation}

It is generally considered that topography was the strongest in. fluencing factor in the placement of structures at Tikal (Carr and Hazard, 1961: 7). The site as a whole is placed along a series of ridges and hills west of the Bajo Santa Fe. The major ceremonial structures and palace groups are situated on a high broken ridge with Temple IV at the western and highest point. The North Zone grouping is placed on a large knob on the north end of the ridge and is connected to Temple IV by a causeway following the narrow crest of the ridge between them. The Temple of the Inscriptions occupies the highest land in its map square. Carr and Hazard (1961: 7) re. port that:

smaller structures are similarly concentrated on level ridges and hilltops, avoiding steep slopes and drainage bottoms. The larger, more important structures are apt to be located on the highest point of a hill, with lesser structures extending down the slopes.

This seems to imply that the size and placement of Tikal house groupings reflects some sort of hierarchy. This assertion was tested by 
comparing the area of house groupings in all but the epi-central area with their elevations. This was first attempted with a Chi-square test, dividing the housemound groupings into three 10-meter classes. Twohundred twenty-six groupings were so studied. The $\mathrm{x}^{2}$ result was 4.30; the required value for significance was 16.9190 with 9 degrees of freedom.

A correlation coefficient of 0.0070 was then obtained for area and elevation of 146 structures. To be significant at the 0.05 level, a result of 0.1946 was needed. At this point, it was questioned whether the lack of significant results in the above tests was due to the use of groupings from such a large area of Tikal. The highest ground on the east side of Tikal was only $200 \mathrm{~m}$., while some areas of western Tikal reached over $250 \mathrm{~m}$. To see if this was influencing the results, only the areas of the 50 groupings of the Encanto Quadrangle were correlated with their elevations. This produced a correlation coefficient of 0.0047 , needing, 0.2875 for significance at the 0.05 level.

From these results, it was concluded that there is no significant relationship between size of housemound groupings and their elevation. The largest structure groupings outside epicentral Tikal are not on the highest ground and there is no observable hierarchy (importanthigher, less important-lower) as suggested by Carr and Hazard. The largest groupings in Square $7 \mathrm{G}$, Structures $7 \mathrm{G} 4.45$ and Structures 7G 17.21 are located at the edge of bajos, on the lowest occupied land in the square, $12 \mathrm{~m}$. below the highest-situated lesser groupings and only $2 \mathrm{~m}$. above the lowest land level in the square. The above-quoted observation of Carr and Hazard can thus be rejected. The role of topography in the placement of housemound groupings cannot be extended beycnd the fact that structures were not built in the low-lying bajos (with a few exceptions) or in very steep areas. This supports the hypothesis that the residential area of Tikal was, by Classic times, filled to the limit imposed by the subsistence system of tree-cropping and kitchen gardening described earlier. If the highest elevations were in fact the most desirable, one might expect that these would be filled by larger groupings, if size of grouping is related to power or influence in the community. Either inhabitants of the larger groupings lacked the coercive power to evict the residents on the highest ground, or (as is more likely) these more elevated areas were not particularly more desirable, since the highest ground is often occupied by small plaza groups with larger ones downslope. 
Analysis of Quarry Locations

Abundant evidence of quarrying was found during the mapping of Tikal. This consisted of tool marks, fine vertical ribbing, grooves, and slots. Where tool marks were not visible, long, straight vertical edges of bedrock or edges zigzagged at right angles provided evidence of quarrying. The most common quarry sites were where blocks were cut from outcrops on the sides of hills. In some more level areas, a large surface area was stripped down as much as $2 \mathrm{~m}$., as in Square 4C just north of Temple IV. Sometimes existing buildings or chultunes were spared in these operations, as in the case of Structures $4049-52$ and Chultun 4C-3. In other cases, existing chultunes were cut into (Chultunes 6G-12 and 3D-10). In some areas large pits were dug, serving first as a quarry site and later as a reservoir, as, for example, the Madiera Reservoir in Square 6D.

Weaver (1972: 155) suggests that the availability of an ample supply of limestone was a major factor in the settlement of Tikal, the central area of which is built on a number of fairly level ridges which would accomodate large ceremonial structures and had outcrops of limestone.

Carr and Hazard (1961: 12) note that quarries are almost always located quite near any large structure and that, whenever possible, construction stone was obtained from the immediate environs of the structure. This statement was tested by comparing the distance between structure groupings and their nearest neighboring grouping with the distance between structure groupings and the nearest quarry site. Of the 581 groupings so tested, 271 , or $46.66 \%$, had a quarry site as their nearest neighbor.

To further test this hypothesis, relationship of smaller structures to quarry sites was studied. The eight central squares of the map which contain the major ceremonial and palace structures, excavated reservoirs, and hundreds of quarry sites were omitted. Carr and Hazard (1961: 4) felt that the pattern of peaks and depressions on the top of a mound usually indicated a ruined vaulted structure beneath. Depressions would thus indicate doorways (which collapse first) or rooms and the high points the remains of transverse walls. An example of this would be Structure 4E-16, represented on the map thus: 


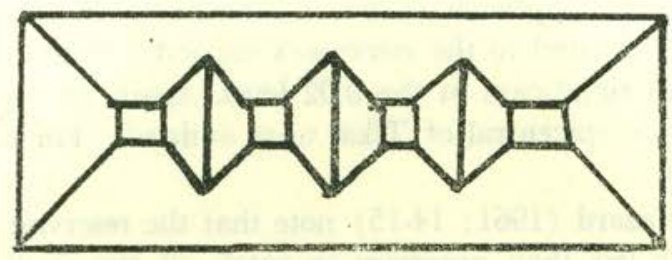

Quarrying is indicated on the map by small x's following the shape of the edge of the cut.

The number of x's in each square were correlated with the number of mounds having a pattern of peaks and depressions. The eight squares constituting the ceremonial heart of Tikal were omitted from this study. The map squares were used as boundaries wherever possible, but the caveat (Hodder and Orton, 1976: 41-43) about the effect of the imposition of a boundary was very much to the point here. Quarry marks from outside a particular square were included in the count for that square if they seemed by eye to be part of a natural cluster transected by the boundary line. Correlation of mounds bearing symbols for vaulted structures with number of quarry marks for 27 map squares produced a correlation coefficient of 0.5365 . Significance at the 0.05 level requires 0.3609 and at the 0.01 level, 0.4869 (Thomas, 1976: 508). This may confirm Carr's and Hazard's hypothesis that mounds with a pattern of peaks and depressions do contain the remains of vaulted structures, if the number of quarry marks on the map are a reliable indicator of the extent of quarry activity in all areas of the site.

\section{Housemound Groupings in Relation to Reservoir Capacities}

Carr and Hazard (1961: 24) give capacities for the Tikal reservoirs, which they graphically computed directly from the contours of the map. Their figures are therefore conservative, because original depths may have been greater, as indicated by the excavations in the Hidden Reservoir which revealed about $2 \mathrm{~m}$. of washed-in sediments above the paved bottom (Carr and Hazard, 1961: 13).

To determine if the capacities of the reservoirs were proportional to the numbers of housemound groupings they might have serviced, distances were measured from each grouping to its nearest reservoir, boundary lines drawn around each cluster, and the number of groupings in each reservoir's "service area" counted. This is basically a 
Theissen Polygon approach (Carr \& Hazard, 1976: 59-60). These counts were compared to the reservoir's capacity, obtaining a correlation coefficient significant at the 0.02 level. Again the structures and reservoirs in the epicentral of Tikal were omitted. (For data, see following page.)

Carr and Hazard (1961: 14-15) note that the reservoir capacity of Tikal was far less than necessary to catch all the available runoff, and calculate that the yearly runoff (based on modern rainfall) from the paved plazas of epicentral Tikal was three times what the reservoirs that collected water from this area were able to store. In the outlying areas, some drainages were artificially shunted around reservoirs (Bejucal and Corriental Reservoirs). More water was available than was necessary to store.

\section{CAPACITY OF RESERVOIRS IN RELATION TO NUMBER OF HOUSEMOUND GROUPING IN SERVICE AREAS OF RESERVOIRS}

\begin{tabular}{lcc}
\hline Water source & $\begin{array}{c}\text { \# of housemound groups } \\
\text { in "Service area" }\end{array}$ & $\begin{array}{c}\text { Distance to center } \\
\text { of Great Plaza }\end{array}$ \\
\hline Palace Reservoir* & $?$ & $220 \mathrm{~m}$. \\
Temple Reservoir* & $?$ & $150 \mathrm{~m}$. \\
Tikal Reservoir & 92 & $1175 \mathrm{~m}$. \\
Corriental Reservoir & 61 & $1290 \mathrm{~m}$. \\
Inscriptions Reservoir & 72 & $1120 \mathrm{~m}$. \\
Causeway Reservoir* & $?$ & $248 \mathrm{~m}$. \\
Bejucal Reservoir & 70 & $1066 \mathrm{~m}$. \\
Madiera Reservoir & 36 & $560 \mathrm{~m}$. \\
Perdido Reservoir & 21 & $1030 \mathrm{~m}$. \\
Hidden Reservoir & $?$ & $320 \mathrm{~m}$. \\
Subin Aguada & 54 & $1275 \mathrm{~m}$. \\
Las Chamchas Aguada & 42 & $1190 \mathrm{~m}$. \\
Pital Aguada & 19 & $1395 \mathrm{~m}$. \\
\hline
\end{tabular}

* These water storage facilities are located in epicentral Tikal and were not considered in my study of the water supply in residential Tikal. 
CAPACITIES OF TIKAL RESERVOIRS (Carr \& Hazard, 1961)

\begin{tabular}{lrr}
\hline & \multicolumn{1}{c}{$M .^{*}$} & \multicolumn{1}{c}{ Gallons } \\
\hline Palace Reservoir & 38680 & 10210000 \\
Temple Reservoir & 271404 & 7175000 \\
Tikal Reservoir & 21060 & 5563000 \\
Corriental Reservoir* & 17380 & 4591000 \\
Inscriptions Reservoir & 15310 & 4045000 \\
Causeway Reservoir & 14270 & 3771000 \\
Bejucal Reservoir & 7380 & 1950000 \\
Madeira Reservoir & 6340 & 1680000 \\
Perdido Reservoir** & 3070 & 812000 \\
Hidden Reservoir*** & 2620 & 693000 \\
Subin Aguada & 400 & 106000 \\
Las Chamacas Aguada & 350 & 92000 \\
Pital Aguada & 310 & 82000 \\
\cline { 2 - 3 } & 154310 & 40770000 \\
\hline
\end{tabular}

Volumes were graphically computed directly from the contours of the map.

* The Corriental capacity was calculated assuming the dike reconstructed to bring the outlet level up to an elevation of $205 \mathrm{~m}$. the elevation of the southern inlet/alternate spillway. The actual water level may have been considerably higher.

** The Perdido capacity was computed assuming the outlet reconstructed so as to hold a meter's depth of water within.

*** The Hidden capacity was computed from the basin contours as they are, without taking into account the greater original depth as shown by excavation.

Correlation coefficient obtained for reservoir capacity vs. number of housemound groups in service area of reservoir $=0.7852$ considering all reservoirs in residential Tikal for which capacities are given. Levels of significance at $0.05=0.6664$, at $0.02=0.7478$, and at $0.01=0.7977$. Discounting Aguada Subin and its service area, correlation coefficient of 0.8151 was obtained. Levels of significance at $0.05=0.7067$, at $0.02=0.7887$, and at $0.01=$ 0.7977 .

The correlation coefficient obtained indicates that the capacity of the reservoirs in the residential districts of Tikal is related to the density of population in the areas around the reservoirs and suggests that the residents had some understanding of their water requirements.

The distance from each reservoir to the center of the Great Plaza was measured to see if this distance would correlate to the capacities of the reservoirs as well. It was postulated that the lessening of population density outward from the center of Tikal might be further confirmed by reservoir capacity. The correlation coefficient obtained (0.5507) almost reached the 0.05 level of significance (0.5529). That it did not reach a significant level is possibly because the outlying area 
south and southeast of the Great Plaza has more densely concentrated structures than the rest of Tikal. A thickened area of the wall of the Mendez Causeway in Square $6 \mathrm{~F}$ may have acted as a dam to hold water draining out of the levelled area in Square 6E. There are also numerous pozos, or small depressions in association with mound groups which may have held water, as near Structures 70-17, 6D-49, 3B-29, and $6 \mathrm{~B}-19$. Numerous other reservoirs are scattered throughout the surrounding countryside, especially east along the edge of the great Bajo Santa Fe where some are used today by temporary chicle camps.

The probability that all sources of water have not been identified, especially in the area mapped by reconnaissance methods only, was taken into account. In the northwest corner of the mapped area there seemed to be far too many structures to have been served by the tiny Aguada Subin. Given the distribution of the other reservoirs, there may have been another source of water north of Aguada Subin in the area mapped by reconnaissance methods only. The groupings closer to the northern boundary of the surveyed area than to Aguada Subin were not counted. Even given this adjustment, it was felt that the housemound count for the Aguada Subin service area was inflated. The count for Las Chanchas service area is also suspiciously large, probably for the same reasons. A correlation coefficient was obtained deleting these two sets of figures, but no appreciably greater level of significance was obtained.

A nearest neighbor analysis was made of the spacing of the fourteen mapped reservoirs and aguadas. $R_{e}$ was $90.36 \mathrm{~mm}, R_{e}$ was 85.33 , and $R$ equalled 1.05 , indicating random spacing. This result was to be expected because factors of soil and landforms must be considerec? before a reservoir is constructed.

In conclusion, there are too many variables and uncertainities for major theories to be based on reservoir placement and capacity in relation to housemound groupings, but these results to suggest that the inhabitants of Tikal were able to estimate their water requirements and build their reservoirs accordingly. If sequences of construction and enlargement of the reservoirs could be established through careful excavation, perhaps the nature of the growth of Tikal could be better understood.

\section{Orientation of the Housemound Groupings to the Cardinal Directions}

The Maya, and many other New World Indians, divided their spatial universe into four parts. Each of these world directions, or 
quarters, had its corresponding god and color (Aveni, 1975: 8-10, 42, 86, 200, 335-6; Marcus 1976: 16-17; Nicholson, 1967: 94-98; Neihardt, 1972: 2; Furst, 1978: 245). The quarters had the following color associations for the Maya:

\begin{tabular}{ll}
\hline \multicolumn{1}{c}{ Quarter } & \multicolumn{1}{c}{ Color } \\
\hline East (likin) & Red (chak) \\
West (chikin) & Black (ek) \\
South (nohol) & Yellow (kan) \\
North (xaman) & White (Zac) \\
\hline
\end{tabular}

Of these four, the eastern quarter, associated among other things with the sun, was dominant and most important. Marcus (1976) has argued that the Maya political organization was consistent with this cosmological view of the universe.

One of the most obvious features of Tikal that the map reveals is that most of the structures are oriented to the cardinal directions and that housemounds are predominantly arranged on four sides of an open plaza. The buildings are rarely exactly parallel or perpendicular to each other, but the error is seldom more than $10^{\circ}$ (Carr and Hazard, 1961: 7). They found that approximately $70 \%$ of all structures were oriented to the right of true north, $10 \%$ to the left, and $20 \%$ on the true cardinal headings. These percentages hold true when the quadrangles were considered separately and when only small structures were considered. The large ceremonial structures are not significantly more accurately oriented than the small house platforms. A sample of the 85 largest structures of the Great Plaza quadrangle revealed that $96 \%$ of these are oriented to the right of true north, $1 \%$ to the left, and $3 \%$ on the true cardinal headings. These results suggest that the Maya cosmological view of the nature of the universe is reflected in their architecture. Haviland's housemound excavation in 1959 revealed structures which were not noticed even after complete bushing on what appeared to be open sides of plazas, Carr's and Hazard's (1961: 8) suspicion that excavations would reveal minor structures on sides of courts that appear open on the map was confirmed. Of 111 mapped features excavated, Haviland found that only four were not the remains of structure while he discovered eleven more which were not rcorded on the map. It is more likely that aberrant features would turn out to be natural than would mounds on the sides of plazas. It (based on Haviland's figures) $3 \%$ of the aberrant (not arranged around plazas or oriented to the cardinal directions) were 
removed and 9\% more mounds added to the open sides of plazas, the plan would appear even more regular and even more in line with Maya cosmology.

Carr and Hazard (1961: 8) report that Wurman noticed in 1958 that on the east side of a number of housemound groups there was a small pyramid or, more often, a small square platform, usually too small to have been a housemound. Examples of this are Structures $6 \mathrm{~F}$ 57-59, 4G 9-12, 3G 30-34, and 70 9-52. These might represent small shrines or ceremonial structures and would fit with the assertion of Marcus and others (above) that East was the most important of the world directions in Maya cosmology. Any special characteristics of the east sides of groupings were recorded to see if the importance of the eastern world direction was reflected in Mayan residential architecture. The results for the 556 groupings studied are:

\section{EASTERN CHARACTERISTICS OF HOUSEMOUND GROUPINGS}

\begin{tabular}{|c|c|c|c|}
\hline & $\begin{array}{l}\text { Percentage } \\
\text { of total }\end{array}$ & Number & Characteristics of eastern side \\
\hline 1 & $23 \%$ & 129 & not applicable-single mounds \\
\hline 2 & $14 \%$ & 77 & $\begin{array}{l}\text { small pyramid or ceremonial structure } \\
\text { on eastern side }\end{array}$ \\
\hline 3 & $23 \%$ & 127 & $\begin{array}{l}\text { open to east-no structure mapped for } \\
\text { eastern side }\end{array}$ \\
\hline 4 & $81 \%$ & 46 & $\begin{array}{l}\text { mound on eastern side too small to } \\
\text { support a house }\end{array}$ \\
\hline 5 & $3 \%$ & 15 & stele on east side of group \\
\hline 6 & $29 \%$ & 162 & normal housemound on eastern side. \\
\hline
\end{tabular}

Minimally, it can be said that $25 \%$ of the housemound groupings have something significant about the eastern side (Categories 2, 4, and 5). If those open to the east are added (assuming either the ceremonial structures on the east were perishable or too small to be noted by the mappers, or that the east side was deliberately left open to the rising sun), $48 \%$ of the groupings have a significant eastern side. If we further deduct the 129 single mounds from the survey, we strengthen the percentage of eastern significance to from $33-62 \%$, depending on whether the groups open to the east are included.

These results should not be assigned any absolute validity, but they are in line with Wurman's 1958 observation and lend some support to the idea that east was the predominant world direction in Maya cosmology and that this is reflected in their architecture. 
Haviland's housemound excavations add further support. He confirmed that small square structures (category 4 above) were shrines and had dedicatory burials beneath them (Haviland, 1965: 18). Further studies of the eastern sides of mound groupings in relation to the rest of the structures in the group could increase our understanding of Maya religion at the domestic level. The emphasis on the east and the world directions in ordinary housemound groupings supports the conclusions that religious activities were carried out at the household level and not only in the large structures in the ceremonial heart of Tikal.

\section{Conclusions}

Spatial analysis of the Tikal map supports Vogt's assertion that the Maya remained predominantely small-hamlet dwellers; at Tikal living in housemound clusters regularly spaced and freely and naturally related to the topography, taking advantage of better building sites and avoiding unfavorable ones, but following no rigid plan or social hierarchy. The results of the nearest neighbor analysis herein reported seem to be in line with the recently-developing picture of Maya subsistence as not being predominantely dependent on maize grown in milpas. Treecropping, infield and kitchen gardening, and care of semidomesticated animals around the housemound groupings is probably responsible for their spacing in what is statistically if not visually a regular manner.

The grouping of an average of 3.6 housemounds around a plaza strongly suggests that the basic social unit was the extended family, which is the standard unit among the modern Maya, whose housing layouts are similar to those at Tikal (Culbert, 1974: 59). The prehistoric housemound groupings at Tikal show evidence that some mounds were added after initial construction as if to accomodate married children and their families.

Given the regular spacing, lack of hierarchial clustering, large number of eastern shrines in housemound groupings, and widespread quarry sites in close association with housemounds which this study reports, it seems likely that the housemound groups were largely autonomous and not rigidly controlled by a central authority. Many archaeologists have seen neighborhood zones at Tikal, each inhabited by a kinship group whose head lived in the most elaborate and largest structure in the zone. Around this unit were clustered the smaller housemound groupings of the lesser members of the kinship group. 
The results of this study do not support this interpretation, and I would agree with Culbert (1974: 59) that kinship organization did not extend above the level of extended families on the basis of spacing of groupings. There is no clear clustering around larger mound groups. Area of housemound groupings is not correlated with elevation or distance from neighboring groupings. Easy availability of building stone may determine the amount of masonry in a structure. Culbert's (1974: 67) assertion that stone construction on housemounds is an indication of wealth is to me insupportable at a site that had such readily available stone in many areas. His picture of an organizational structure based on neighborhood units is likewise not enhanced by this study, alhtough it does not contradict his acceptance of a cargo system operating in the Classic period, as part of the religious, political, and economic system of Tikal.

The orientation of housemounds to the cardinal directions and the emphasis on the east in the placement of family shrines underscores the importance of religion and cosmology in the daily lives of the residents of Tikal.

As yet, the hierarchial nature of Tikal's social and political system cannot be described. This study seems to indicate that it was not overpowering. Stripping of surfaces for stone, presumably for large religious structures, often avoided existing housemounds and chultunes of no particular importance. Small groupings maintained their position on the highest, best drained land. No grid pattern or communication arteries were imposed on the site outside its ceremonial heart. Size of housemound groupings range over a wide continuum from very small to moderately large, and do not conveniently fit a hierarchy.

While there existed a central authority in Classic times powerful enough to oversee the construction of the defensive earthworks to the north and south and carry out massive construction projects in the heart of Tikal, this study implies that despite this central authority, there was much individual family autonomy in residential Tikal. The settlement pattern of Tikal seems, as Stierlin suggested, to have been freely, naturally, and humanely related to the environment, subsistence pattern, and fundamental character and cosmology of its inhabitants.

\section{Acknowledgements}

I would like to thank the following for help and encouragement in the preparation of this paper: Professor T. Douglas Price, Professor James B. Stoltman, and Jefferey A. Behm of the Department of Anthropology, UWMadison, and Professor William Denevan of the Department of Geography, UW-Madison. 


\section{SOURCES CITED}

Aveni, Anthony F.

1975 Archaeoastronomy in Pre-Columbian America. University of Texas Press, Austin.

BRonson, BenNeT

1978 "Ankor, Anuradhapura, Prambanan, Tikal: Maya Subsistence in an Asian Perspective". In Harrison and Turner, 1978: 225300 .

CARr, Robert F. and James E. Hazard

1961 Tikal Report \# 11, Map of the Ruins of Tikal, El Peten, Guatemala. Museum Monographs, The University Museum, University of Pennsylvania, Philadelphia.

Culbert, T. Patrick

1974 The Lost Civilization: The Story of the Classic Maya. Harper and Row, New York.

Furst, Jill LesLie

1978 Codex Vindobonensis Mexicanus I: A Commentary. Institute for Mesoamerican Studies Publication \# 4. State University of New York at Albany.

Hamblin, Robert L. and Brian L. Pitcher

1980 "The Classic Maya Collapse: Testing class conflict hypotheses". American Antiquity, 45 (2): 246-267.

Hammond, NoRman

1978 "The Myth of the Milpa: Agricultural Expansion on the Maya Lowlands". In Harrison and Turner, 1978: 23-34.

Harrison, Peter D. and B. L. Turner II

1978 Pre-hispanic Maya Agriculture. University of New Mexico Press, Albuquerque.

Haviland, William A.

1963 Excavation of Small Structures in the Northeast Quadrant of Tikal, Guatemala. Ph. D. Dissertation, Department of Anthropology, University of Pennsylvania, University of Microfilms, Ann Arbor.

1965 "Prehistoric Settlement at Tikal, Guatemala". Expedition, 7 (3): 14-23.

1969 "A New Population Estimate for Tikal, Guatemala". American Antiquity, 34: 429-433.

1970 "Tikal, Guatemala and Mesoamerican Urbanism". World Archaeology, 2: 186-197.

1972 "Family Size, Prehistoric Population Estimates and the Ancient Maya". American Antiquity, 37 (1): 135-139.

Hodder, Ian and Glive Orton

1976 Spatial Analysis in Archaeology. Cambridge University Press, Cambridge.

Marcus, Joyce

1976 Emblem and State in the Classic Maya Lowlands. Dumbarton Oaks, Washington, D. C.

Millon, Rení

1976 "Social Relations in ancient Teotihuacán". In Eric R. Wolf (ed.), The Valley of Mexico, Studies in Pre-Hispanic Ecology and Society. University of New Mexico Press, Albuquerque. 
Nicholson, Irene

1967 Mexican and Central American Mythology. Paul Hamlyn, New York.

NeIHaRdT, John G,

1972 Black Elk Speaks. Pocket Books, New York.

Olson, Gerald W.

1969 "Description and Data on Soils of Tikal, El Peten, Guatemala, Central America". Mimeo, 69-2, Department of Agronomy, Cornell University, Ithaca.

Pinder, David; Izumi Shrmada, and David Gregory

1979 "The Nearest Neighbor Statistic: Archaeological Application and New Developments". American Antiquity, 44 (3): 430-445.

Price, T. Douglas

1978 "The Analysis of Lithic Artifact Distribution and Association on Prehistoric Occupation Floors". In D. D. Davis (ed.), Lithics and Subsistence: The Analysis of Stone Tool Use in Prehistoric Economies. Vanderbilt University Publications in Anthropology, 20: $1-33$.

Puleston, Dennis E.

1965 "The Chultuns of Tikal". Expedition, 7 (3): 24-29.

1971 "An experimental approach to the function of Classic Maya chultuns". American Antiquity, 36: 322-335.

1973 Ancient Maya Settlement Patterns and Environment at Tikal, Guatemala: Implications of Subsistence Models. Ph. D. Dissertation. University Microfilms, Ann Arbor, 74-14128.

1974 "Intersite areas in the vicinity of Tikal and Uaxactun". In Norman Hammond (ed.), Mesoamerican Archaeology: New Approaches. Duckworth, London: 303-311.

1978 "Terracing, Raised Fields, and Tree Cropping in the Maya Lowlands: A New Perspective on the Geography of Power". In Harrison and Turner, 1978: 225-246.

Puleston, D. E. and Donald W Gallendar

1967 "Defensive earthworks at Tikal". Expedition, 9 (3): 40-48.

Rige, Don S.

1978 "Population growth and subsistence alternatives in a tropical lacustrine environment". In Peter D. Harrison and B. L. Turner II, Pre-hispanic Maya Agriculture. University of New Mexico Press, Albuquerque: $35-61$.

Sanders, William $\mathrm{T}$.

1973 "Cultural Ecology of the Lowland Maya: A Reevaluation". In T. Patrick Culbert (ed.), The Classic Maya Collapse. University of New Mexico Press, Albuquerque, 329-365.

Stein, Julie; Jennifer Moody, and Vicky Walsh

MS a Settlement Pattern at Tikal: A Computer Analysis, Spring, 1976. Department of Anthropology, University of Minnesota.

MS b Settlement Pattern at Tikal: A Computer Analysis, Spring, 1977. Department of Anthropology, University of Minnesota.

Stierlin, Henri

1964 Living Architecture: Mayan. Grosset and Dunlap, New York. 
TURNER II, B. L.

1976 "Population density in the Classic Maya Lowlands: New evidence for old approaches". Geographical Review, 66 (1): 73-82.

1978 "The development and demise of the swidden theses of Maya agriculture". In Peter D. Harrison and B. L. Turner II (eds.), Pre-hispanic Maya agriculture. University of New Mexico Press, Albuquerque.

Vogr, Evon Z.

1969 Zinacantan: A Maya Community in the Highlands of Chiapas. Harvard University Press, Cambridge.

Weaver, Muriel Porter

1972 The Aztecs, Maya, and their Predecessors; Archaeology of Mesoamerica. Seminar Press, New York.

Whallon, Jr., Robert

1974 "Spatial Analysis of Occupation Floors II: The Application of Nearest Neighbor Analysis". American Antiquity, 39 (1): 16-34. 